\title{
Study of the Influence of Subtle Energetic Changes in Environment on the Productivity of the Process of Sleep
}

\author{
Edward V. Krizhanovsky ${ }^{*}$, Lim Kwong Choong2 \\ ${ }^{1}$ Moscow Technical University of Communications and Informatics, Moscow, Russia \\ ${ }^{2}$ BAE International Inc. SDN BHD, Plaza Pengkalan, Kuala-Lumpur, Malaysia \\ Email: ${ }^{*}$ edward@telebiomet.ru
}

Received 9 June 2014; revised 2 August 2014; accepted 12 August 2014

Copyright (C 2014 by authors and Scientific Research Publishing Inc.

This work is licensed under the Creative Commons Attribution International License (CC BY). http://creativecommons.org/licenses/by/4.0/

(c) (i) Open Access

\begin{abstract}
An experiment was conducted to study human activity after sleeping using two types of mattresses. One was ordinary mattress with a basis of cotton eco-friendly materials. Another one was an analog which was exposed to activation in the area of natural energy fields in Malaysia. The results reveal a significant effect of activated mattresses on the human psychophysiological and energy states.
\end{abstract}

Keywords

Ecosystem, Luscher Test, Crownscopy, Human Health

\section{Introduction}

One of the major factors affecting human health is a rational combination of sleep and wakefulness. It is considered that it is necessary to give to a dream approximately 8 hours daily. Deprivation of a dream leads to disorders of the nervous and endocrine systems, weakening of the immune system and other vital body functions. But contemporary active person, quite often is sleeping for 5 to 6 hours. In that case, it is important to create the most comfortable and correct conditions for restoration of organism energy resources in these hours.

The comfort is caused not only in what room the person sleeps, whether there are no foreign sounds or smells, but also directly on what kind of object he sleeps on. The most important element of a full, restful night's sleep is a mattress. We got used to the most widespread qualitative sign of a mattress - its density, the ability to adapt to the human body.

${ }^{*}$ Corresponding author.

How to cite this paper: Krizhanovsky, E.V. and Choong, L.K. (2014) Study of the Influence of Subtle Energetic Changes in Environment on the Productivity of the Process of Sleep. Open Journal of Ecology, 4, 693-702.

http://dx.doi.org/10.4236/oje.2014.411059 
However it is only mechanical influence. In this case effective interaction of the material of which the mattress is manufactured with the internal environment of the human body is not observed. Therefore we set for ourselves the task - to investigate those mattresses which passed not only a production way at factory, but also in addition were exposed to activation in the area of natural energy environment.

This work is devoted to revealing the differences between the states of volunteers using an ordinary mattress (OM) with a basis of cotton eco-friendly materials of filler and cover, and also analog whose basis was exposed to activation (AM) in the area of natural energy fields in Malaysia within 1 day.

\section{Materials and Methods}

\subsection{Experimental Tools}

\subsubsection{Crownscopy}

Crownscopy is a method to evaluate Psychophysiological and Energy state of a person based on the analysis of crown discharge captured around the one's fingers in a high frequency electromagnetic field [1]-[3].

Crownscopy is caring out with "Crownscope" device. "Crownscope" works in the following manner. The patient's finger is placed on the transparent dielectric plate with conductive coating on the reverse side. Then pulses from the generator are brought to the electrode. These pulses create electromagnetic field around the examined object. As a result, crown luminescence appears around the finger. It is captured with the help of an optical system and a CCD camera and converted into video signals which are saved as AVI files in the computer memory, where the digital signal is converted into a two-dimensional dynamic distribution of the finger emission which corresponds to the patient's state. The output signal from the computer becomes an input for the data representation block where it is visualized as a two-dimensional dynamic image with certain geometric and brightness properties on a part of the screen. When compared to the sample image of a practically healthy patient the examined patient's state is determined.

Biophysics of the Crownscopy Method. Emission of electrons and photos from the skin surface is stimulated with short (1 - 5 microseconds) pulses of electromagnetic field (EMF). According to the measurements taken with the help of the pulse oscilloscope equipped with memory, a series of electric current pulses (and luminescence) appears during the EMF pulse, each of them lasts for about 100 microsec. The pulse is developed due to the ionization of molecules of the gas environment because of the emitted electrons and photons. The drop of the pulse is explained with the charge of dielectric surface and the appearance of EMF gradient directed opposite to the initial field. When a series of stimulating EMF pulses with the frequency of $1000 \mathrm{~Hz}$ is created the emission processes are developed within the time of pulse duration. This time is not enough for the ion depolarization processes in tissues to develop, which is why the current appears due to the electron movement along the structural complexes of biological tissue in the pulse current flow. Based on this, we can conclude that the Crownscopy method allows to judge about the level of Energy reserves indirectly on the molecular level of structural protein complexes.

Organ and neuro-skin relationships and local capillary blood flow in the skin are the main components that contribute to the type of the skin luminescence in electromagnetic field.

Human's skin and nervous system share a common ectodermal origin. Nerve impulses, which come from the organs, change the functional state and the colloidal structure of the nerve fiber, then they are reflected in the periphery not only directly, but also because of the influence of the vascular wall on the electric potential, and through this fact they are reflected in the dielectric constant of the blood and lymph. As a result a kind of "Flow of Electric Energy" is formed. It affects the properties of the skin which characterize the patient's physiological and psychological state. This becomes the dominant factor in the creation of the pattern of optoelectronic luminescence of skin.

The fact that the patient can see the luminescence around their fingers raises more visual interest and appears a very attractive aspect of the method.

\subsubsection{Blood Pressure}

In this work the standard systolic and diastolic pressure were measured.

\subsubsection{Stange Probe (Breath-Holding Test) Introduction}

A test used as a rough index of cardiopulmonary reserve, measured by the length of time a person can hold ones 
breath. Diminished cardiac or pulmonary reserve is indicated if one's breath is held for less than 20 seconds [4] [5].

\subsubsection{Luscher Test}

The Luscher color test is a psychological test invented by Dr. Max Luscher in Basel, Switzerland. Luscher believed that sensory perception of color is objective and universally shared by all, but that color preferences are subjective, and that this distinction allows subjective states to be objectively measured by using test colors.

It was proposed that because the color selections are guided in an unconscious manner, they reveal the person as they really are, not as they perceive themselves or would like to be perceived.

The results of the Luscher-Color-Diagnostic contain indications pertaining to personal assessment and special, professional recommendations as to how psychological stress and the resulting physical symptoms can be avoided. It also offers additional information for verbal and homeopathic therapy.

Proponents of the test claim this method allows a rapid and deep personality analysis from only this color ranking information.

We used Lusher's eight-color test and his modification "Paired comparisons" which is common in practice of psycho-diagnostics. The technique of color psychodiagnostics "Paired comparisons", representing the modified version of the short (eight-color) test of Lusher, was developed at the Faculty of Psychology of the St. Petersburg University by Yu. I. Filimonenko, V. Yu. Rybnikov, Yu. and V. Gorsky in 1994 [6].

The main characteristics (ideas) of color preferences and interpretation of the ones relations are detailed stated in a number of works [6]-[9]. Here it seems appropriate to point out a number of important provisions. The place of a color is a numerical expression of ones position in a number of preferences. The most preferred color (chosen as the first) takes the 1st place. The most rejected-the 8th place. As Lusher's each color corresponds to a certain psychophysical contents, the appearance of color in most areas of preference or rejection allows doing the conclusion about special conditions of the examinee.

The analysis of interpretations of the color choices which are available in the manual of Lusher, allowed to assume that a ratio of places of some pairs of colors encompasses additional diagnostic information and can serve as a basis for an assessment of negative psychological states [6] [9].

The parameters of norm are well-known [9] (Table 1).

The vegetative coefficient is an additional parameter to Lusher's test. The Vegetative Coefficient offered by the Hungarian psychologist K. Shiposh [10]. One reflects physiological domination of sympathetic or parasympathetic divisions of vegetative nervous system.

The average norm for Vegetative coefficient parameter lies within the boundaries of $0.6-1.1$ points. Vegetative coefficient values 1.0 - 1.5 points are the most favorable for maximum realization of all human performance in stressful situations. This corresponds to the optimal degree of sympathetic dominance and the related energy of organism mobilization.

Vegetative coefficient values above 1.5 points indicate the presence of the subject's overexcitation, excess of holding-down tension. Vegetative coefficient values less than 1.0 points correlate with the dominance of the parasympathetic division of the autonomic nervous system and indicate the predominance setting to rest and minimize their own efforts.

Table 1. Lusher's test parameters in norm.

\begin{tabular}{cc}
\hline Test indicator & Standard group \\
\hline Mental fatigue & $7.02 \pm 0.30$ \\
Mental tension & $4.41 \pm 0.53$ \\
Anxiety & $5.15 \pm 0.40$ \\
Emotional stress & $6.70 \pm 0.52$ \\
Working capacity & $5.37 \pm 0.20$ \\
Total deviation & $13.63 \pm 1.12$ \\
Vegetative coefficient & $1.21 \pm 0.14$ \\
\hline
\end{tabular}




\subsection{Experimental Methods}

To obtain significant results we organized double blind scheme of experiment.

We collected volunteers in volume of 40 practically healthy people in 20 - 26 year old interval. People was divided in 4 group with 10 people in each one.

The analysis of human state was done with the help of next methods: Crownscopy (modern method of c physiological and energetic status), blood pressure, Shtange probe (adaptation) and Luscher test (stress and psychological factor measurement).

First group was TRULY informed that they took influence with AM during 30 min rest.

Second group was WRONGLY informed that they took influence with AM (in fact they used placebo cover) during 30 min rest.

Third group was WRONGLY informed that they use placebo cover during $30 \mathrm{~min}$ rest, but in fact they were used AM.

Forth group was TRULY informed that they take placebo during 30 min rest.

After 30 min rest and influence of mattresses we conducted all described above measurements again. The Figure 1 and Figure 2 shows examples of the use of different mattresses.

Then we compared and analyzed all results and made scientifically significant conclusions.

Comparison between experimental groups was done by approximately 30 parameters from the mentioned techniques.

On the basis of the described methods of experiments, we obtained the following parameters were analyzed by the statistical significance of changes before and after test:

Front Area (of total crown discharge for all fingers), Left Area (of total crown discharge for all fingers of left hand), Right Area (of total crown discharge for all fingers of right hand), Symmetry of field (\%) (of total crown discharge for left and right hands); Irregularity, Front Entropy, Number of systems in dysfunction (of total crown discharge for all fingers), Number of problems in psychosomatic, Number of energy centers in dysfunction (by value in crownscopy), Number of values in the energy centers dysfunction (by symmetry in crownscopy), Adaptation (by dynamic of crown discharge in time), Blood pressure, Subjective estimation of own state (on a 5-point scale), 7 parameters of Lusher test (including vegetative coefficient) (see Table 2).

\section{Results}

Statistically significant differences were found for the following parameters: Entropy, which characterizes the order of distribution of the energy field (crownscopy); the number of energy centers in dysfunction (crownscopy); adaptation, which characterizes the energy reserves of the organism (crownscopy); Stange test; Lusher test; a subjective assessment.

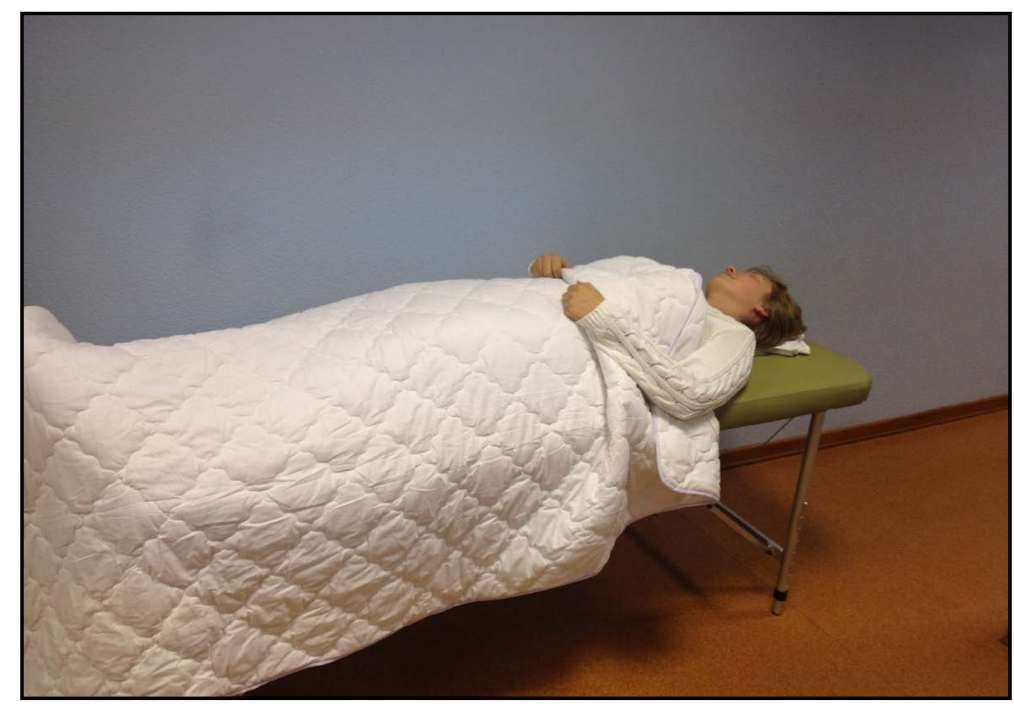

Figure 1. Test with activated mattress. 
The results of changes in term of Crownscopy, Stange test and Subjective assessment parameters is represented at Table 2 and Figure 3.

Below are given average images, Tables and Figures for the states for the different experimental groups (Table 2, Table 3, Figures 4-10).

\section{Discussion}

The parameters which are mentioned at the tables above all have the statistically significant differences.

Samples contained 10 volunteers in each group, and had a normal distribution. For this reason, t-test was

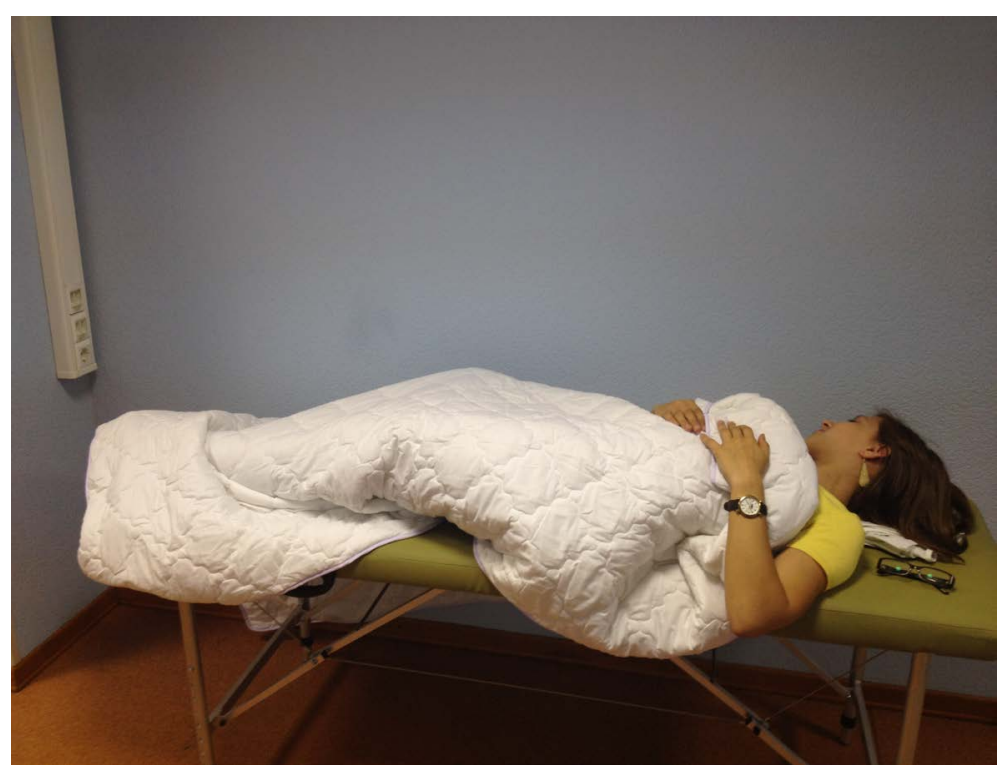

Figure 2. Test with conventional mattress.

Table 2. The changes of experimental parameters after and before using mattresses (crownscopy and other).

\begin{tabular}{cccccc}
\hline \multirow{2}{*}{$\begin{array}{c}\text { Experimental } \\
\text { groups }\end{array}$} & $\begin{array}{c}\text { Entropy } \\
\text { (crownscopy) }\end{array}$ & $\begin{array}{c}\text { Number of energy } \\
\text { centers in dysfunction } \\
\text { (crownscopy) }\end{array}$ & $\begin{array}{c}\text { Adaptation } \\
\text { (crownscopy) }\end{array}$ & Stange test (sec.) & $\begin{array}{c}\text { Subjective } \\
\text { assessment }\end{array}$ \\
\hline Group 1 & $-0.11 \pm 0.02$ & $1.3 \pm 0.25$ & $3 \pm 1.25$ & $17 \pm 6$ & $1 \pm 0.50$ \\
Group 2 & $-0.05 \pm 0.03$ & $0.2 \pm 0.12$ & $2.2 \pm 2.12$ & $5 \pm 4$ & $0.2 \pm 0.30$ \\
Group 3 & $-0.08 \pm 0.03$ & $0.6 \pm 0.20$ & $2.8 \pm 1.20$ & $12 \pm 5$ & $0.8 \pm 0.50$ \\
Group 4 & $-0.04 \pm 0.02$ & $0 \pm 0.05$ & $1 \pm 2.30$ & $3 \pm 8$ & $0 \pm 0.5$ \\
\hline
\end{tabular}

Table 3. The changes in Lusher test parameters in ratio of after and before using mattresses.

\begin{tabular}{cccccccc}
\hline \multirow{2}{*}{$\begin{array}{c}\text { Experimental } \\
\text { groups }\end{array}$} & $\begin{array}{c}\text { Mental } \\
\text { fatigue }\end{array}$ & $\begin{array}{c}\text { Mental } \\
\text { tension }\end{array}$ & Anxiety & $\begin{array}{c}\text { Emotional } \\
\text { stress }\end{array}$ & $\begin{array}{c}\text { Working } \\
\text { capacity }\end{array}$ & $\begin{array}{c}\text { Total } \\
\text { deviation }\end{array}$ & $\begin{array}{c}\text { Vegetative } \\
\text { coefficient }\end{array}$ \\
\hline Group 1 & $-1.4 \pm 0.06$ & $-1.3 \pm 0.05$ & $-1.8 \pm 0.05$ & $-1.6 \pm 0.08$ & $1.2 \pm 0.1$ & $-3.5 \pm 0.12$ & $0.15 \pm 0.021$ \\
Group 2 & $-0.42 \pm 0.12$ & $-0.41 \pm 0.11$ & $-0.8 \pm 0.22$ & $-0.5 \pm 0.15$ & $0.3 \pm 0.15$ & $-0.5 \pm 0.21$ & $0.1 \pm 0.12$ \\
Group 3 & $-1 \pm 0.08$ & $-0.8 \pm 0.8$ & $-1.6 \pm 0.1$ & $-1.2 \pm 0.09$ & $0.8 \pm 0.1$ & $-2.5 \pm 0.15$ & $0.13 \pm 0.053$ \\
Group 4 & $-0.38 \pm 0.1$ & $-0.36 \pm 0.15$ & $-0.5 \pm 0.18$ & $-0.4 \pm 0.15$ & $0 \pm 0.12$ & $-0.2 \pm 0.12$ & $0 \pm 0.14$ \\
\hline
\end{tabular}




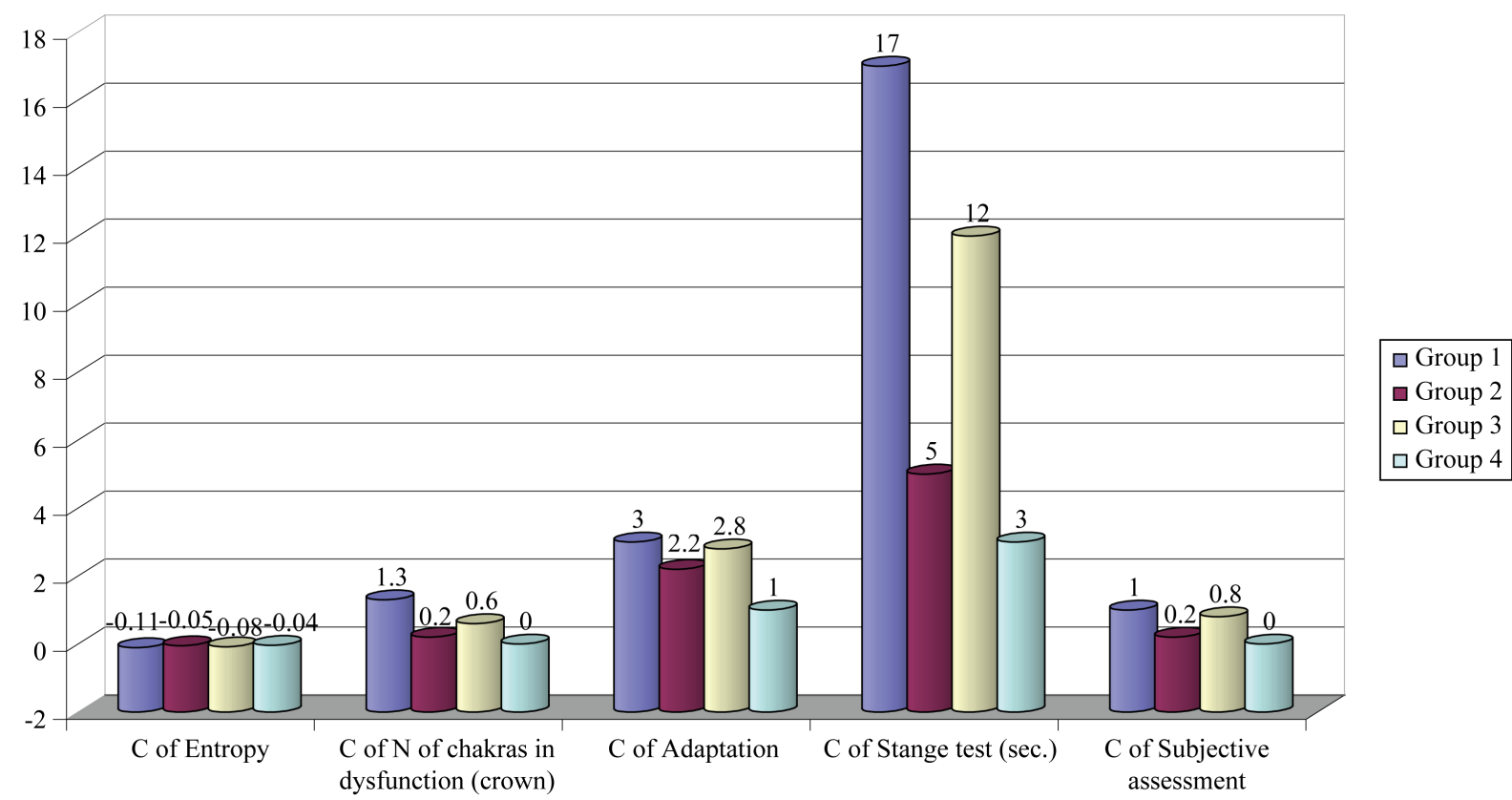

Figure 3. Changes in term of Crownscopy, Stange test and Subjective assessment parameters.
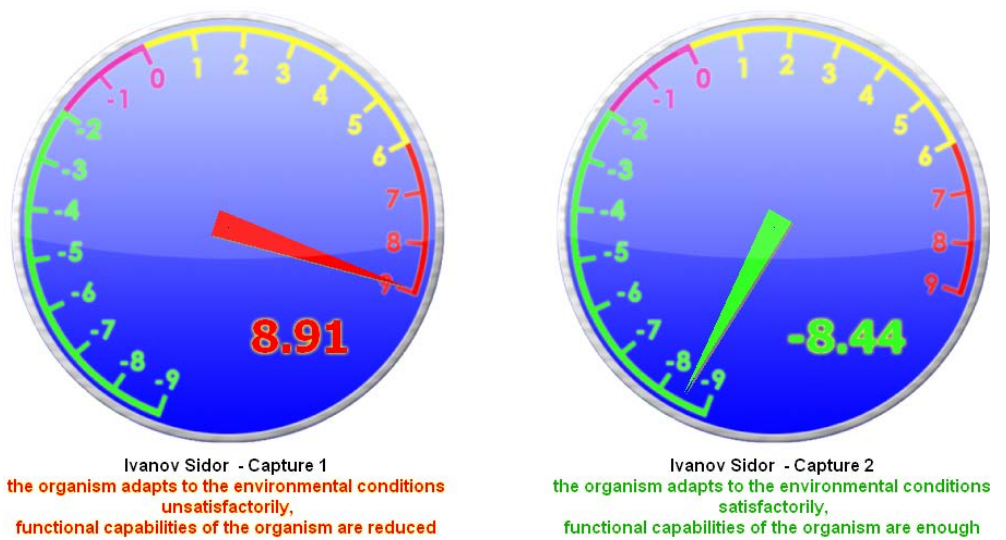

Figure 4. Average differences between the parameter of adaptation-the Energy reserves of the organism (crownscopy) before and after the rest (30 minutes) with AM.
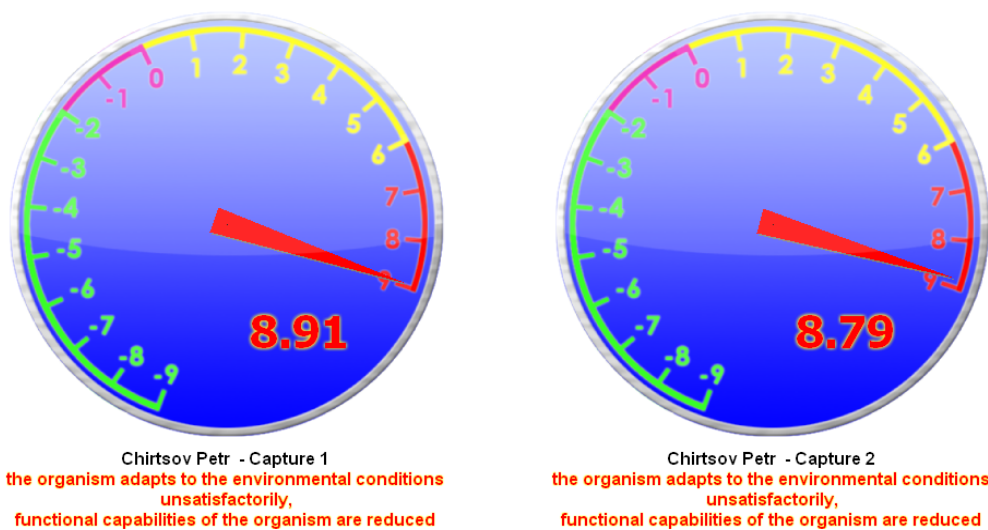

functional capabilities of the organism are reduced

Figure 5. Average differences between the parameter of adaptation-the Energy reserves of the organism (crownscopy) before and after the rest (30 minutes) with conventional mattress. 


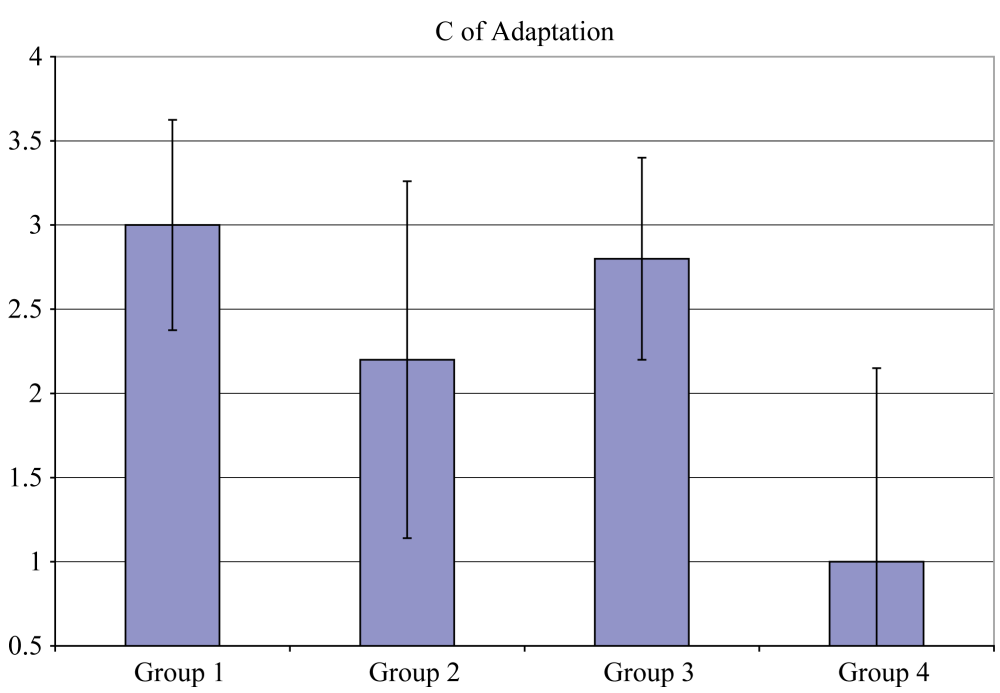

Figure 6. Changes before and after test in term of Adaptation parameter for all groups with trusting intervals.

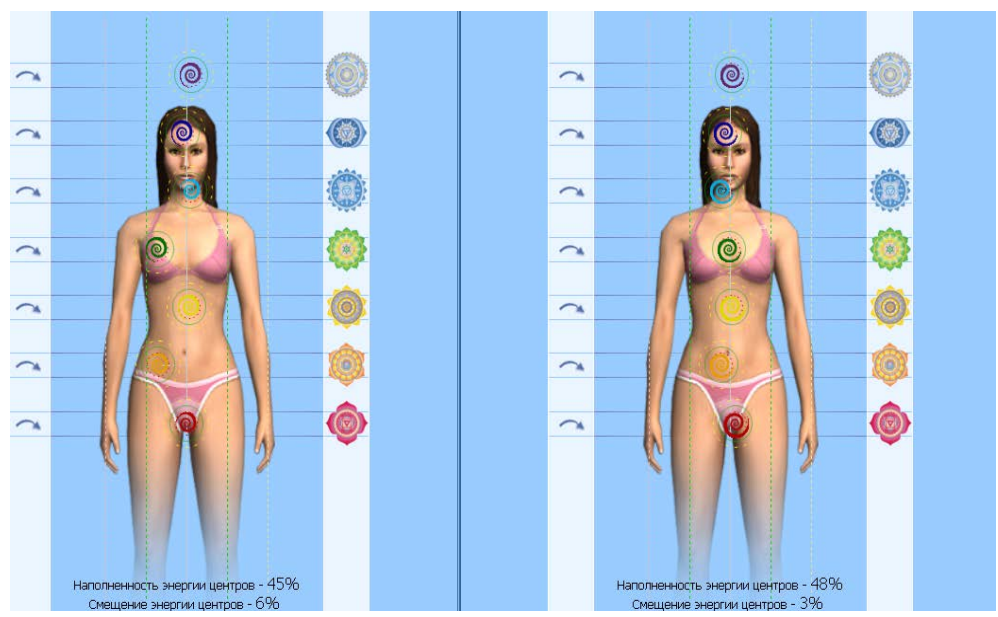

Figure 7. Average differences between the states of the energy centers and one disbalance before and after the rest (30 minutes) with AM.

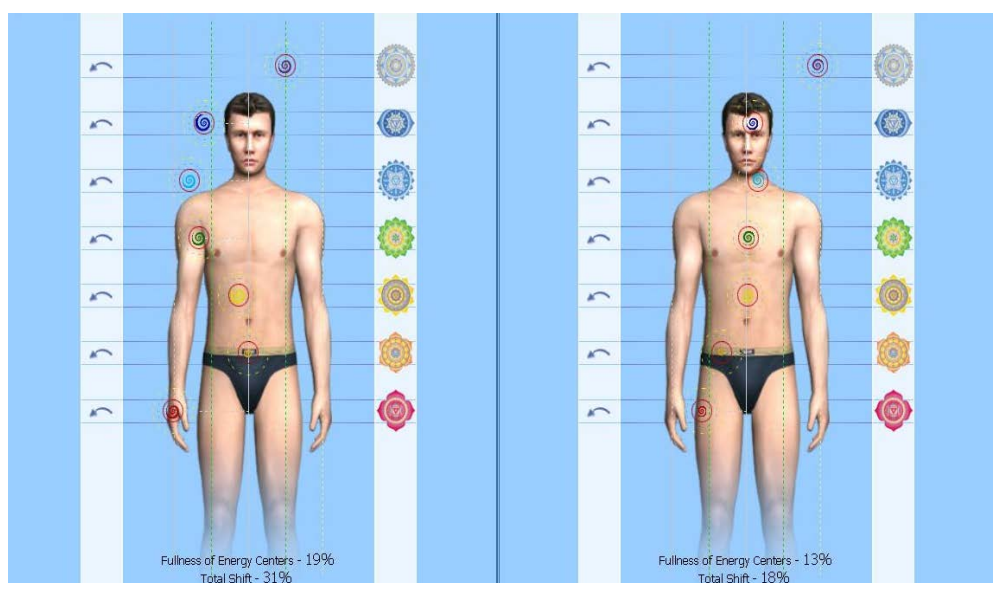

Figure 8. Average differences between the states of the energy centers and one disbalance before and after rest (30 minutes) with conventional mattress. 


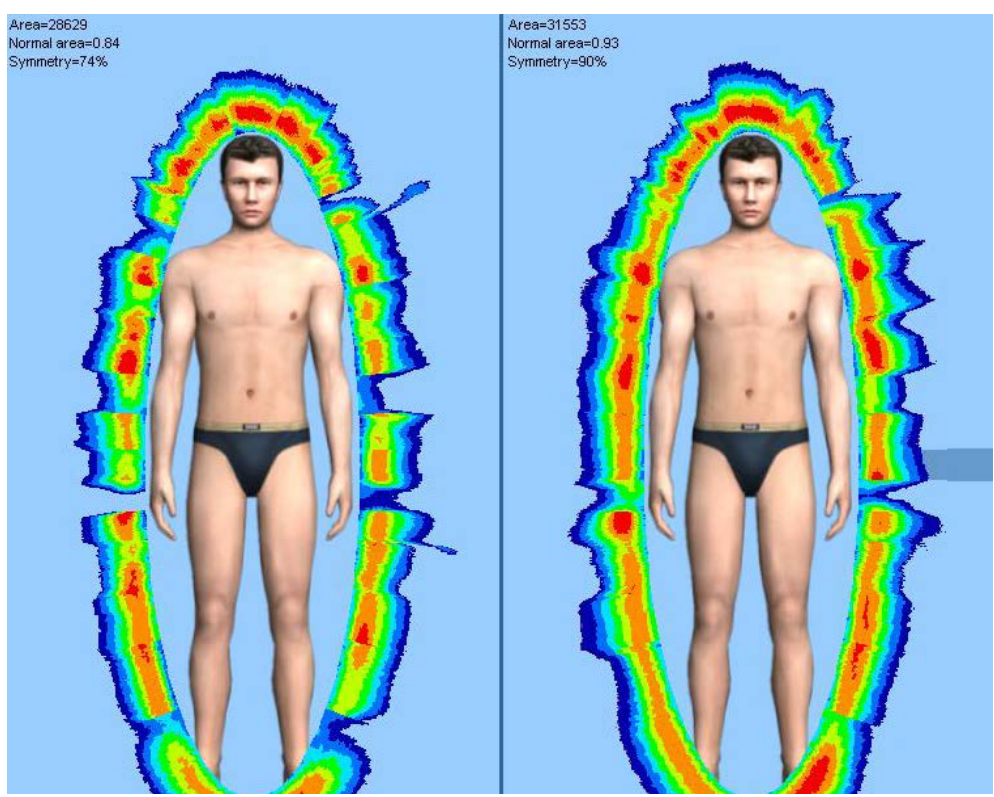

Figure 9. Average differences between energy states (crownscopy) before and after the rest (30 minutes) with AM.

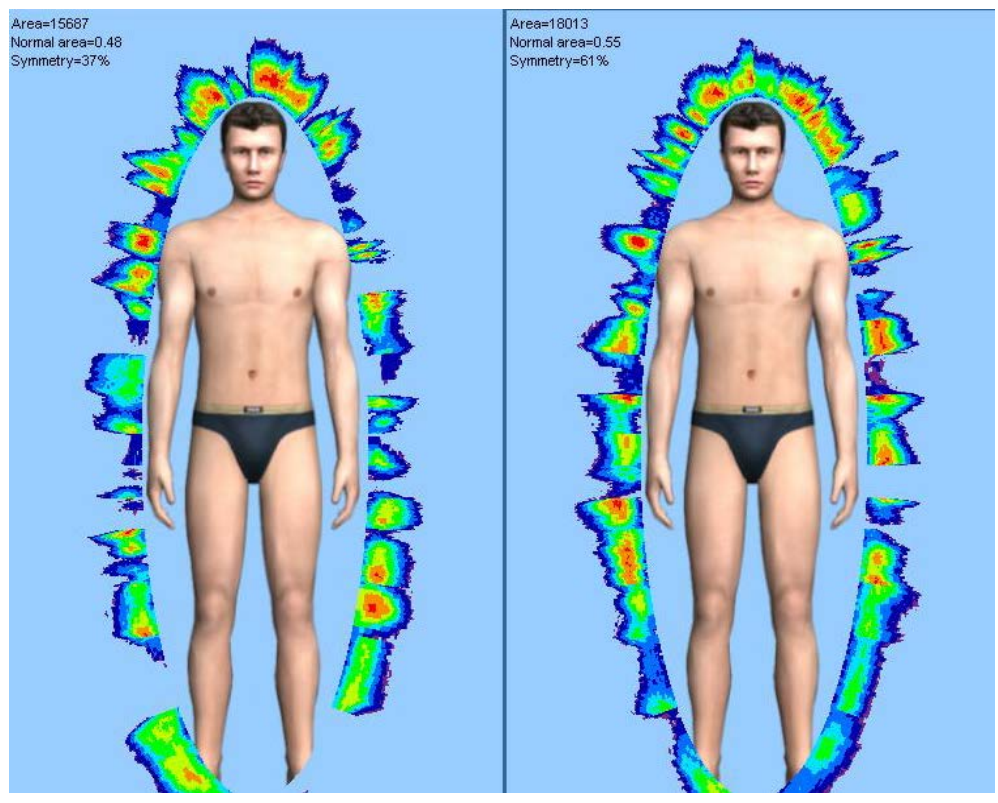

Figure 10. Average differences between energy states (crownscopy) before and after the rest (30 minutes) with conventional mattress.

chosen for analysis of statistical significance. To simplify the discussion, the statistical probability (in the cases with statistically significant difference by the groups) are indicated at the end of the statements. The criterion of significance was selected as $\mathrm{P}=0.05$.

So, on the basis of Table 2 and Table 3, as well as Figure 3 and Figure 6, we can make the next conclusions.

The "Entropy" change in Group 1 (which used the AM and was aware of this) is statistically significantly differ from the corresponding parameter in Group 4 (which used OM and were aware of this) $(\mathrm{P}<0.02)$.

Since the Entropy parameter in crownscopy characterizes the disorder of Energy in the human organism, then the difference between two groups suggests that in Group 1, we have greater growth of order in the distribution of Energy in the organism relative to the Group 4. 
At the same time, a Group 3, which also used AM (they were wrongly informed that they use OM) also showed increase of order in the distribution of Energy in the organism relative to the Group $4(\mathrm{P}<0.04)$. At the same time, a Group 2 (which used OM, however, they were wrongly informed that they use OM) showed no difference with the Group 4. Consequently, an increase of order and increase of Energy balance by crownscopy, using the AM is reliable.

"Number of centers in dysfunction" parameter by crownscopy means the value of Energy centers (responsible for endocrine glands states) which are in dysfunction. Changes of this parameter, which is given in Table 2 and Figure 3, Figure 7, Figure 8 describes the increase of the number of Energy centers which have become to the normal state from the Energy deficit or Energy excess.

Group 1 is statistically significantly different from Group 4 and Group 2 by this parameter $(\mathrm{P}<0.01)$. Similarly, Group 3 is also statistically significantly different from Group 4 and Group 2 (P $<0.04$ ). Therefore, the transition of the functional state of Energy centers from the interval of hypofunction to the interval of norm for a given crownscopy parameter, is significant in case of using AM.

"Adaptation" parameter by crownscopy is a measure of Energy reserves in the organism. Positive changing of one means increasing the Energy reserves in the testing process.

Group 1 was significantly different from Group $4(\mathrm{P}<0.04)$ by this parameter. However, Groups 2 and 3 do not have similar differences with the Group $4(\mathrm{P}<0.10)$ (Figure 6). Thus, we can say that the differences by this parameter (when using the AM and $\mathrm{OM}$ ) are available, however, it is possible that they are presence due to placebo effect.

Difference of "Stange test" parameter means decreasing of oxygen dependent Energy deficit in the testing process.

Group 1 is statistically significantly different from Group 4 and Group $2(\mathrm{P}<0.02)$ by this parameter. Similarly, Group 3 is also statistically significantly different from Group 4 and Group 2 ( $\mathrm{P}<0.040$ and $\mathrm{P}<0.045$ ). Consequently, the use of AM, can promote to reduce oxygen dependent Energy deficit during testing process.

The change of "Subjective assessment" parameter characterizes the change of the subjective health state in the process of testing. Positive changing of this parameter, tells about subjective improvement of the feeling of own health state.

Group 1 is statistically significantly different from Group 4 and Group $2(\mathrm{P}<0.035)$ by this parameter. Similarly, Group 3 is also statistically significantly different from Group 4 and Group 2 ( $\mathrm{P}<0.038$ and $\mathrm{P}<0.041$ ). Consequently, the use of AM can facilitate the improvement in subjective estimation of own health state during testing process.

On the basis of obtained data it is clear (Table 3) that after relaxation the values of Mental fatigue, Mental tension, Anxiety, Emotional stress, Total deviation are decreasing in all cases. Thus in case of Group 1 these differences are statistically significant by all parameters. In case of Group 3 statistically significant differences are exists by Mental fatigue and Anxiety parameters $(\mathrm{P}<0.01)$. This is, most likely, caused by placebo effect which is strengthens possible influence of a mattress.

At the same time, working capacity at all groups also increases, except in Group 4 case. Thus changes by this parameter are statistically significant also at the cases of Group 1 and Group $3(\mathrm{P}<0.018$ and $\mathrm{P}<0.02)$.

Vegetative coefficient also increases at all surveyed subjects except Group 4. Thus, increases don't exceed 1.5 values, i.e. influences don't lead to overexcitation or excess holding-down tension. At Group 4 case decrease of Vegetative coefficient less than 1 were observed for some subjects. This is evidence of predominance setting to rest and minimize their own efforts.

Thus, according to the parametric Luscher test analysis, in cases of Group 1 and Group 3 there are statistically significant decrease of the values for the next parameters under the influence of a AM: Mental fatigue, Anxiety and Total deviation. At the same time for these groups the values of working capacity and Vegetative coefficient are increasing. This indicates an improvement in the psycho-physiological status, which is necessary for maximum realization of all human performance in daily activity.

\section{Conclusions}

The rest for 30 minutes with an AM mattress is characterized by a greater stabilization of the human Energy state, improved balance of Energy, increasing Energy resources estimated by crownscopy, compared to conventional mattress. 
At the same time one revealed the decrease of oxygen dependent Energy deficit during the testing process and the subjective improvement of the feeling of own health state.

Some results may be caused due to the placebo effect.

According to parametric Luscher test analysis, in case of groups, which used AM obtained statistically significant decrease of the values for the next parameters: Mental fatigue, Anxiety and Total deviation. At the same time for these groups the values of working capacity and Vegetative coefficient are increasing. This indicates an improvement in the psycho-physiological status, which is necessary for maximum realization of all human performance in daily activity.

There have been individual cases of improved conditions on the background of a headache, back pain and insomnia. However, these cases require more extended research on described dysfunction.

\section{Acknowledgements}

“Hai-O Enterprise Bhd” leading by Tan Kai Hee, Cahirman and Tan Kee Hock, Managing Director.

\section{References}

[1] Boyers, D.G. and Tiller, W.A. (1973) Corona Discharge Photography. Journal of Applied Physics, 44, 3102-3112. http://dx.doi.org/10.1063/1.1662715

[2] Krizhanovsky, E. and Lim, K.C. (2005) Influence of Subtle Energetic Change in Water on the Human Energy State. Journal of Subtle Energies \& Energy Medicine, 15, 147-161.

[3] Krizhanovsky, E., Lim, K.C. and Tan, S.C. (2005) Influence of Energetic Water on the Quality of Life. Journal of Food, Agriculture \& Environment, 3, 351-354.

[4] Stange, V.A. (1914) About Prediction under Anesthesia. Russian Doctor, 3, 73-74. (In Russian)

[5] Shaefer, K.E. (1975) Neural Control of $\mathrm{CO}_{2}$ - Receptors Responce to Hyper-Capnia in Man. Journal Applied Physiology, 38, 900-906.

[6] Filimonenko, I., Rybnikov, V.Y. and Gorsky, Y.I. (1994) Method of Pairwise Comparisons. Voenizdat, Moscow.

[7] Anastazi, A. (1982) Psychological Testing. Book1. Pedagogika, Moscow.

[8] Lüscher, M. (1995) Signals of Personality. MODEK, Voronezh.

[9] Rybnikov, V.Y. and Zavalishin, D.A. (1998) “Operational Monitoring” of Automated System. NOR-TSYABP, St. Petersburg.

[10] Shiposh, K. (1980) Significance of Autogenic Training and Bio-Management with a Feedback of Electric Activity if Brain in Neu-Rosis Therapy. Ph.D Dissertation, Leningrad State University, Leningrad. 
Scientific Research Publishing (SCIRP) is one of the largest Open Access journal publishers. It is currently publishing more than 200 open access, online, peer-reviewed journals covering a wide range of academic disciplines. SCIRP serves the worldwide academic communities and contributes to the progress and application of science with its publication.

Other selected journals from SCIRP are listed as below. Submit your manuscript to us via either submit@scirp.org or Online Submission Portal.
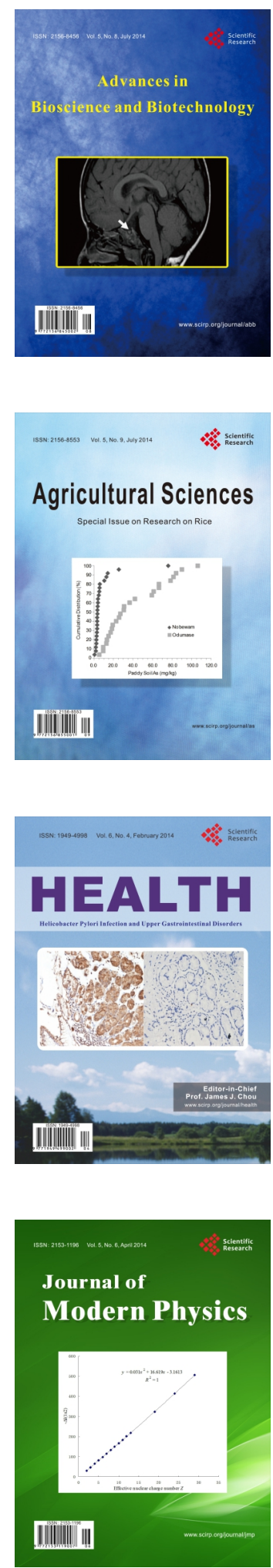
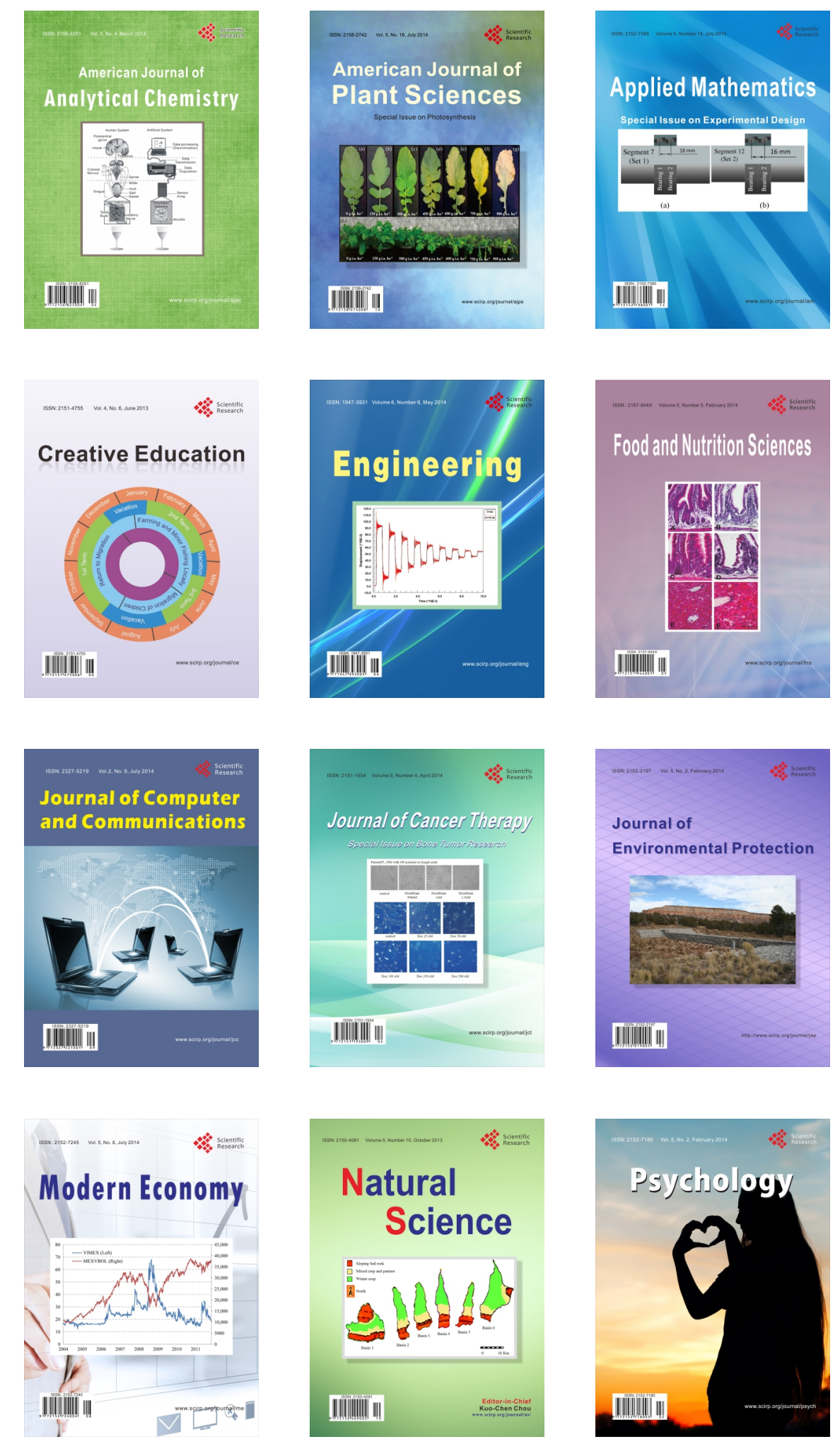